DOI: http://dx.doi.org/10.5915/30-1-16282

\title{
Marlboros and Milkshakes: Deconstructing the Slippery Slope
}

I was at a party recently where the discussion turned to the issue of the 41 state lawsuits against the tobacco industry and the plans for a federal settlement which would preempt further class action lawsuits by smokers. A friend said, "How can you sue someone for producing and selling a legal product? Will McDonalds be next for making milkshakes that contribute to heart disease?" This slippery slope of logic has been actively promulgated by the tobacco industry in an effort to make any product liability seem unreasonable. Why not coffee, candy or cake?

I must first acknowledge that I am not an impartial observer to this legal, political and public health debate. I published research in 1991 which showed the impact of tobacco advertising on young children. ${ }^{1}$ In this study, children as young as three years could match Camel's Old Joe character with a cigarette. By age six, this rate of matching was nearly universal and similar to the children's matching of Mickey Mouse with the Disney channel logo.

As is customary, the tobacco industry attacked the research and sought to ruin my academic career. This took the form of a three year legal battle with RJ Reynolds over my research records, including the names of the children who participated in the study. In the end, Reynolds was given permission by the Court to examine every document in my research files; however, the confidentiality of the children's identities was preserved.

During the past year I have served as an expert witness in the cases brought by the Attorney Generals of Florida, Mississippi, and Texas. In this role, I have reviewed numerous industry documents that prove the tobacco industry broke the law. It is this criminal behavior, and not the magnitude of the public health problem caused by smoking, which forms the basis of the state cases.

This is not to minimize the public health problem. Smoking is the only legal product that will kill you when used precisely as suggested by the manufacturer. Most smokers become addicted. One third of regular users die prematurely from a smoking related illness. This is responsible for an average decrease in life expectancy of seven to ten years. There is no other legal or illegal product that comes close to matching the suffering caused by cigarettes; however, this does not constitute breaking the law! The state cases are based on illegal activities by the tobacco industry to enhance and secure their market for cigarettes.

First, the industry knew that their product was addictive and specifically tailored the delivery of nicotine to promote and maintain addiction. For years, the industry has claimed that nicotine was not addictive and that people smoked for "taste." It is now very clear that tobacco manufacturers understood the role of addiction in the use of tobacco. Tobacco is blended and additives are mixed in order to deliver a precise amount of nicotine to the smoker. The industry had specific knowledge of the physiology and pharmacology of its product. This knowledge was in fact at the core of its marketing strategy, since "casual" teenage experimentation with cigarettes often leads to life long use. Smokers buy and use cigarettes, despite desperately wanting to quit. The industry understood that their product was a drug, yet sold it under the laws relating to food, which violates federal law. While milkshakes may be tasty, they are not addictive.

The second illegal activity is the promotion of cigarettes to those too young to legally buy and use them. It is very clear from industry documents that they understood that brand loyalty was created during the period of teenage experimentation. To sell Marlboros to adults, it was necessary that children prefer Marlboro. It is therefore no surprise that the majority of advertising was targeted at youth. Manufactures claimed that this targeting was at "young adults" who could legally smoke, but subpoenaed documents show a different story. Marketing research was done on teenagers as young as 14 and ad campaigns were consistently designed to influence those too young to legally smoke. Unlike McDonalds and milkshakes, it is illegal for RJ Reynolds to market cigarettes to children. 
Finally, the industry actively conspired to deceive the public about the harms of smoking. This was far more than an innocent claim that "We do not have enough science to know the risk." The tobacco manufactures and their lawyers organized public relations strategies to attack any report linking smoking with disease. To this day, their official position is that smoking does not cause cancer. To hold this view is one thing, but to actively misrepresent the scientific facts about the harm that your product causes is quite different. It is very likely that many smokers would have quit long ago if the industry had not been so effective in portraying the scientific facts as an ongoing "debate." In contrast, McDonalds has never conspired with Burger King to mislead the public about the health consequences of obesity.

State Attorney Generals have brought suits against tobacco manufactures not because smoking causes death and disease, but rather, because these manufacturers have broken the law. It is one thing to unintentionally sell a defective product. It is quite another to sell a product with the intent to addict users, to illegally target children, and to hide the facts about the product's risk.

1998 will be a pivotal year for the cigarette industry in the U.S. This is an industry that has already agreed to pay over $\$ 300,000,000,000$ to avoid future class action liability. How much is it willing to pay for political access this year to influence the debate in Washington? If the past is a predictor of the future, it is likely that the tobacco industry will get a federal bill that will "look tough" but have sufficient loopholes to permit continued success for Marlboro. It must not be forgotten that even though the percentage of Americans who smoke has decreased, the number of smokers today is unchanged from the day that the first Surgeon General's report was made public.

Finally, for readers of this journal, it is important to realize that the U.S. is on the cuffing edge of this issue. Tobacco manufactures are repeating the American experiment in countries around the world. In 1997 Phillip Morris for the first time, made more profit in its international cigarette business than it did in the U.S. For tobacco companies; the answer to the question "What's next?" is not "milkshakes, coffee, candy or cake," but rather, "Pakistan, India, China and Egypt."

\section{References}

1. Fischer PM, Schwartz MP, Richards JW, et al: Brand logo recognition by children aged 3 to 6 years. JAMA $1991 ; 266: 3145-8$.
Paul M Fischer, MD Center for Primary Care Augusta, Georgia 